\title{
DETERMINATION OF ENGINEERING DIGITALIZATION MATURITY
}

\author{
Tafvizi Zavareh, Mona; \\ Eigner, Martin \\ Institute of Virtual Product Engineering; University of Kaiserslautern
}

\begin{abstract}
Engineering Digitalization enables development of new high intelligent products containing mechanical, electrical, software and communication components. As these complex products are result of multidisciplinary engineering processes, digitalization also enforces companies to raise, adapt and revise their engineering competencies and process capabilities to increase agility and maintain competitiveness. Also, the growing amount of data related to product and processes requires a wellstructured management concept. In order to encounter all these changes and new requirements companies should identify their specific strengths and weaknesses and derive needs for action. This paper presents a novel maturity model for evaluation of capabilities of Engineering Digitalization in areas of processes, products, services, data, human and organization. The maturity model enables the detection of enhancement potentials and conception of individual digitalization plans for production companies. It has been composed based on a proven multidisciplinary engineering methodology along the product lifecycle process, which includes Model Based Systems Engineering Methods, and a multilevel IT architecture integration concept.
\end{abstract}

Keywords: Systems Engineering (SE), Digital / Digitised engineering value chains, Product Lifecycle Management (PLM), Maturity Model, System Lifecycle Management

\author{
Contact: \\ Tafvizi Zavareh, Mona \\ TU Kaiserslautern \\ MV \\ Germany \\ tafvizi@mv.uni-kl.de
}

Cite this article: Tafvizi Zavareh, M., Eigner, M. (2021) 'Determination of Engineering Digitalization Maturity', in Proceedings of the International Conference on Engineering Design (ICED21), Gothenburg, Sweden, 16-20 August 2021. DOI:10.1017/pds.2021.119 


\section{INTRODUCTION}

In the future, the Internet of Things and Services (IOT/IOS) assume connected products and services. Electronics and software will continue to increase in this type of products, systems and embedded services. If products communicate with each other over the Internet, they are called Cyberphysical or Cybertronic systems. These directions will have several consequences: interdisciplinary, regionally and organizationally distributed and integrated product development, a rethinking of today's design processes, methods, IT solutions and organizational forms, as well as the demand for end-to-end processes based on digital models from the requirements definition, system architecture, product development, simulation, production planning, to production, service and operation. Furthermore, planning and design methodologies of all disciplines - mechanics, electronics and software - must be put to the test and their suitability for a new approach to product and service development must be reviewed in order to convert them into a common, integrated and interdisciplinary method, process and IT solution approach. This approach of digitalizing products, systems, services and their development is called Engineering 4.0. The basics are methods of Systems Thinking (ST), Advanced Systems Engineering $(A S E)$ and Model Based Systems Engineering (MBSE). The digitalization of products, systems and services means a transformation process that rearranges the classic boundaries of a fragmented and competing IT solution world, away from silo thinking to a consistent integrative approach in engineering. A lightweight and federated engineering backbone will play the role of data and process integration throughout the entire Product Life Cycle (PLC), including service operations. Another key point of digitization is the horizontal and vertical integration of intellectual, technical and administrative work processes along the PLC (Eigner, 2021). However, it is still unclear how companies can explicitly approach digitalization and digital transformation and can realize it in a structured way. In fact, digitalization is only the means and not the goal and should make the organizations more efficient, productive and ultimately profitable.

The maturity model presented in this paper enables the detection of enhancement potentials and conception of individual digitalization plans for production companies. This maturity model has been composed based on a proven multidisciplinary engineering methodology along the product lifecycle and integrates further organizational technological and human aspects. It allows a company to compare its performance in different fields according to the goal state and reveals individual potentials and challenges.

\section{STATE OF THE ART IN DIGITALIZATION OF ENGINEERING}

\subsection{The VPE System Development Methodology}

The VPE System Development Methodology ${ }^{I}$ defines a holistic macro approach. It adopts and combines concepts of different interdisciplinary and discipline-specific development approaches and adapts them to the requirements and boundary conditions of cybertronics. Based on the definitions of a methodology according to Martin (1997) and Estefan (2008), the methodology consists of the following three essential components (cf. Figure 1):

- $\quad$ the Model Based Virtual Product Engineering (MVPE) process model is adapted to the context of the Internet of Things and interdisciplinary design

- $\quad$ the Kaiserslautern System Concretization Model (KSCM) is positioned as the correspondent Design Method

- a 5-Level IT Architecture concept based on a multilevel Engineering Backbone.

While the MVPE model - with a specific focus on conceptual design and development - describes the general life cycle phases of a product development process, the KSCM bundles techniques to fulfil the tasks that arise during the phases of conceptual design and discipline-specific development (i.e. a method). The 5-level IT architecture concept describes a complementary approach for the tool-based creation and management of system data along the entire life cycle. The main changes in the product and process world are, on the one hand, completely new requirements for products and production systems ${ }^{2}$

\footnotetext{
1The VPE System Development Methodology has been developed since 2014 in several research projects funded by the Federal Government by the Institute of Virtual Product Engineering (VPE). Eigner (2021)

2 In the following the term product is used for the product and the production system
} 
(Ashton, 2009) and service-oriented business models as well as new IT technologies, architectures and standards (big data, 3D printing, OSLC/ REST, multi-tenant data bases,) that enable the implementation of these requirements. The digitalization of products and product development means a transformation process that rearranges the classic boundaries of a fragmented and competing IT solution world. A consistent, lightweight and federated engineering backbone will play the role of data and process integration between product and production development, production/manufacturing and assembly, and service. In extension to the traditional PLM approach the central Engineering Backbone solution is called System Lifecycle Management (SysLM) (Eigner, 2014, 2021). SysLM extends the PLM approach upstream (full integration of system modelling) and downstream (integration of engineering and production planning) and is based on actual WEB-based software technology. For the mental transformation of silo-oriented thinking on an interdisciplinary and system-technical approach and the ITimplementation of Engineering 4.0, MBSE, ST, ASE and SysLM can serve as a central guideline.

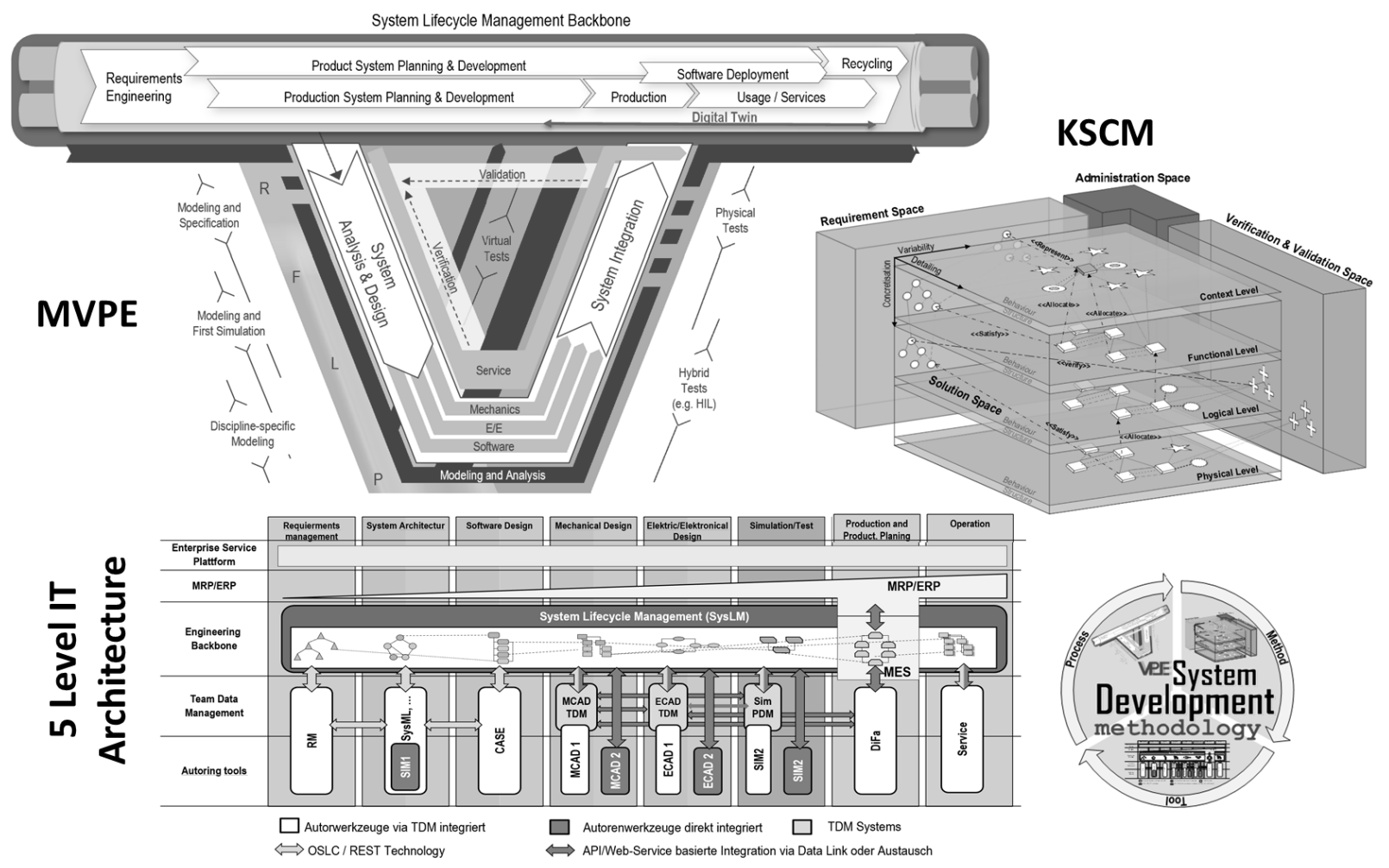

Figure 1. VPE system development methodology (Dickopf, 2020; Eigner et al., 2019; Eigner, 2021)

\subsection{Digitalization of Engineering (Engineering 4.0)}

Digitization - as the first step towards a Digital Transformation - is the process of converting analogue information into a digital format. Digitalization - as the second step - indicates a process of continuous change triggered by the growing usage of digital technology within products and processes. Digital technologies are causing significant change along the value chain and creating strategic potential for companies and organizations. However, companies must attempt to manage the structural changes and organizational barriers that influence the positive and negative outcomes of this process (Vial, 2019). Digitalization in the context of engineering is understood as:

- the digitalization of products, systems and services

- the vertical and horizontal digitalization of the engineering processes.

The functional range of current mechatronic systems is significantly extended by mutual networking and influencing. If these systems communicate with each other - usually via the Internet - we speak of Cyberphysical systems (CPS) or Cybertronic systems (CTS). Both represent a further development of mechatronic systems in the direction of intelligence and communication capabilities. Building on model-based development, research is currently being conducted on approaches for the interdisciplinary and integrated development of CTS, which include products, production systems and serviceoriented business models, so-called Product Service Systems (PSS) (Aurich et al., 2019; Eigner et al., 
2017). Based on communicating 'things' ( $\rightarrow$ products/systems), new, often disruptive service-oriented business models are built for various applications, e.g. Smart Products, Smart Factory, Smart Energy, Smart Mobility, Smart Farming and Smart Buildings. Services within new overall systems are becoming the central success factor of the Internet of Service (IOS). If companies build a service-oriented business model on digitized products and processes, it is called Digital Transformation.

Another key aspect of digitization is the horizontal and vertical integration of technical and administrative work processes along the product life cycle. Horizontal integrations focus on the administrative functions such as Release, Change and Configuration Management over the entire product life cycle and the integration of all information generated in the individual phases on the SysLM level. Vertical integrations are the integration of authoring systems via Team Data Management (TDM) or direct into SysLM along the life cycle phases requirements management, system architecture, design in mechanics, electronics and software and simulation (Figure 2). As of today, no company in the world has implemented such a complete vertical and horizontal integration, but only fragmentary approaches. But it is precisely from the experience with these approaches that we can learn. The concepts are available and the first partial prototypes have been built. The process of an overall integration that lies ahead of us is evolutionary, just like the progress in the last 50 years of the use of optimization solutions in engineering. The engineering-relevant processes, methods and IT solutions are available. They must now be applied to all phases of the PLC.

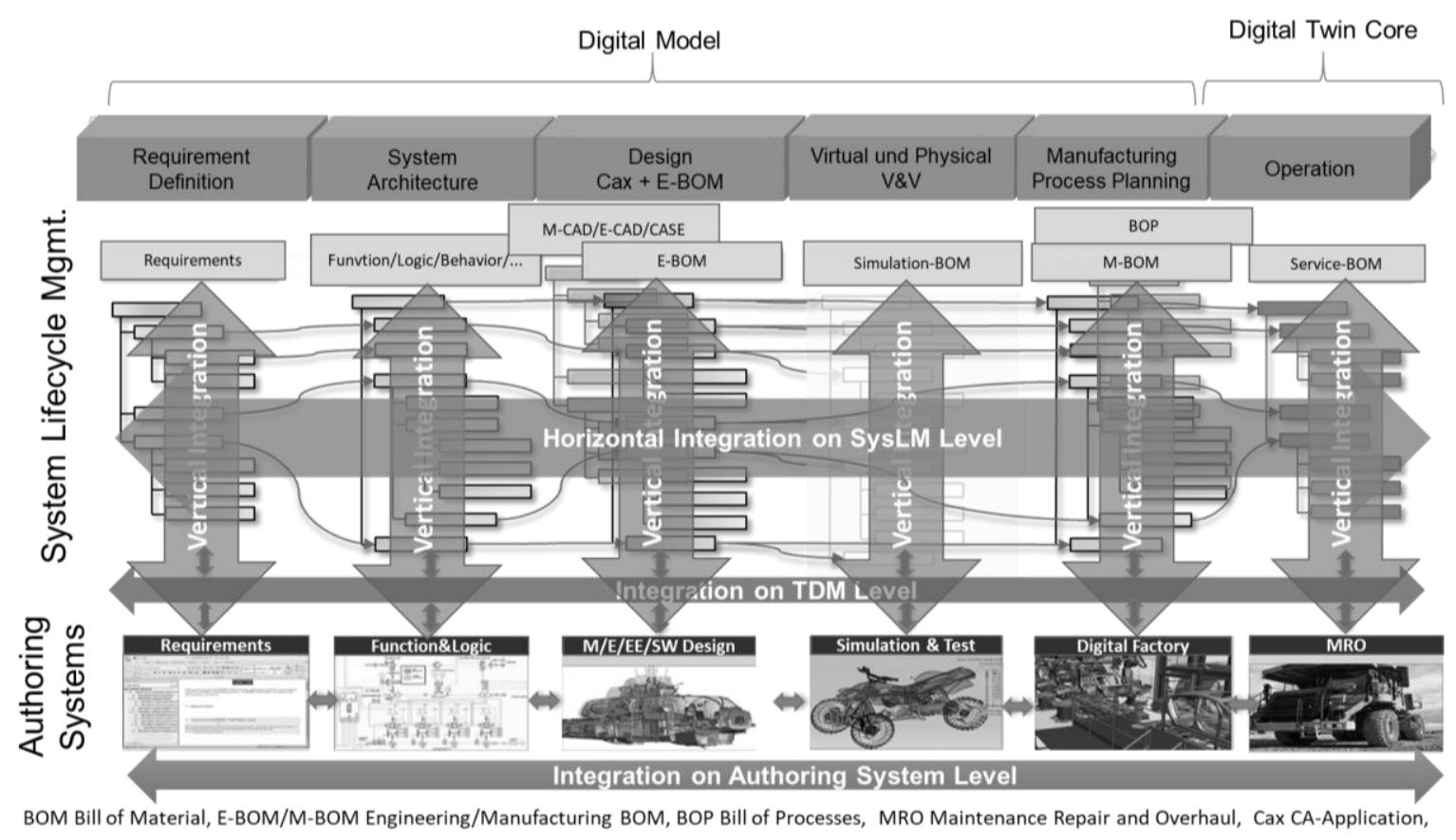

Figure 2. Vertical and horizontal integration of the engineering processes

Based on this discussion important requirements of implementation of the engineering digitalization can be summarized to connectivity of engineering data and processes, MBSE and ST methods and engineering IT Tools. VPE System Development Methodology integrates these aspects and can be considered as a basic reference model for implementation of engineering digitalization. The presented VPE System Development Methodology and the digitalization of engineering based on this are the framework for the maturity model introduced in the following. With the help of this maturity model, the understanding and implementation of the theoretical background can be improved and a roadmap containing individual potentials and needs can be derived.

\section{MATURITY ASSESSMENT}

As mentioned above, companies are under increasing pressure to innovate and improve their products, reduce time to market and cut costs. The implementation of suitable technologies, processes and methods in engineering is the basis for mastering new challenges, especially with regard to digitalization (Gausemeier et al., 2017; Abramovici, 2018; Tafvizi Zavareh et al., 2018). The development of cybertronic products (also referred as smart products) and their service systems as a main challenge for 
the companies requires multidisciplinary collaboration, integrated processes, and availability (traceability) of data and information throughout the entire PLC (Eigner, 2021). For this reason, companies strive to update their digital skills according to their needs.

Furthermore, to make best strategic options, companies are hold to determine their own strengths and weaknesses and identify their potential and risks (Wagner et al., 2017; Issa et al., 2017). The introduction and integration of new technologies in terms of an integrated digitalized engineering requires extensive well-studied planning and thus financial and human resources that are often missing. Based on a comprehensive, founded self-assessment, future needs for action can be easily derived and possibilities for achieving higher effectiveness, innovativeness, adaptability and profitability can be identified (Reichert, 2020; Bauer et al., 2019). Also identifying deficits can reveal neglected or less focused, but not unimportant areas and indicate necessary changes within a company.

To obtain a reasonable holistic view of company's engineering development degree, not only products, but also processes, technologies, organizational conditions, staff competencies and strategies must be thoroughly evaluated (Gausemeier et al., 2002). For this purpose, the progress level can be evaluated by means of a digital maturity assessment in order to advance and ultimately validate the company's level of digitalization (Schumacher et al., 2019).

\subsection{Maturity Models}

Maturity models are often used as a tool to measure the maturity of an organization or process in relation to a specific target state (Stich et al., 2019). These tools help to identify and assess the current state of an organization using various criteria. Based on the results action fields can be spotted and recommendations for action can then be derived. According to Becker et al (Becker et al., 2009), a maturity model consists of a sequence of maturity stages for a class of objects. It represents an assumed, aspired or evolutionary path, which the considered objects pass through in discrete stages. Typically, these objects are organizations or processes (Bundschuh et al., 2005). The lowest stage represents an initial state, which is characterized by the fact that the organization has hardly any capabilities in the considered area. The highest maturity stage, however, stands for a mature state.

Maturity models refer to the level theory by Nolan as part of his IT Management concept, which states that elements of a system pass through a sequence of different development phases over time. The properties of the different phases must be distinguishable and empirically verifiable, and it must be possible to understand what causes an element of a system to advance to the next phase of development (Nolan, 1973). In order for a system to ascend a development phase, all properties of the current phase must be fulfilled first. The origin of these models is the Quality Management Maturity Grid (Crosby, 1979) developed by Philip B. Crosby. This is a five-stage matrix whereby organizations can evaluate the maturity of their service and quality management processes.

At the end of the 1980s, the Capability Maturity Model (CMM) appeared, which is designed to reveal improvement opportunities in the software development process (Humphrey, 1988). This model was then further developed by Ahern et al (2003) into the Capability Maturity Model Integrated. Besides this model, the model for Software Process Improvement and Capability Determination (SPICE), which was developed by the international standardization organization ISO, is one of the most widely used maturity models (Ahern et al., 2003) (ISO, 2015). Automotive SPICE is a domain-specific variant of the international standard of the German Association of the Automotive Industry (VDA). The purpose of Automotive SPICE is to evaluate the performance of the development processes of control unit suppliers in the automotive industry (VDA QMC Working Group 13, 2017; Höhn et al., 2015).

In recent years a variety of maturity models were developed mostly based on the structure of general models (CMMIs and SPICE) which aim to measure the maturity of companies with focuses on latest related topics to the industry. Figure 3 shows some of these maturity models identified in the recent literature concerning the requirements mentioned in chapter 2.2 (Schuh et al., 2020; Lichtblau et al., 2015; Jodlbauer and Schagerl, 2016; Leyh et al., 2016; Batenburg et al., 2006; Klötzer and Pflaum, 2017; Berghaus, Sabine and Back, Andrea, 2016; Pfenning et al., 2020; Vogelsang, 2018; Schumacher et al., 2019).

\subsection{Identified Research Gap}

To select or pursue a model, it is important to clarify the objectives of the model and structure one's own needs. Although there are a variety of models already existing (cf. Table2), the reviewed litera- 
ture lacks an engineering-specific maturity model, which should simultaneously address digitalization, MBSE and the integration approach to SysLM.

Another striking characteristic is the background of the here presented model. The majority of the available models are based on a collection of best practices, whose implementation is recommended. They refer to themselves as reference models and follow different sources for each criterion. However, the VPE Engineering Digitalization Maturity Model (VPE-EDMM) aims to present a step-by-step approach for the implementation of the well-founded VPE System Development Methodology, which integrates the mentioned important aspects in sections 2.1 and 2.2. into a holistic matter.

\begin{tabular}{|c|c|c|c|c|c|c|c|c|}
\hline \multirow[b]{2}{*}{ Autor } & \multicolumn{3}{|c|}{ Maturity model focuses on } & \multicolumn{5}{|c|}{ Maturity model contains specific criteria for implementation of } \\
\hline & Digitalization & $\begin{array}{l}\text { Product/ System } \\
\text { Lifecycle } \\
\text { Management }\end{array}$ & Engineering & $\begin{array}{l}\text { Horizontal PLC } \\
\text { Integration }\end{array}$ & $\begin{array}{c}\text { Vertical } \\
\text { PLC Integration }\end{array}$ & MBSE Methods & $\begin{array}{l}\text { verified own } \\
\text { Methodology }\end{array}$ & $\begin{array}{c}\text { Culture and } \\
\text { Organization }\end{array}$ \\
\hline Schuh et. al. & $\bullet$ & $\bullet$ & $\bullet$ & $\bullet$ & $\bullet$ & $\mathbf{D}$ & $\bullet$ & - \\
\hline Lichtblau et. al. & $\bullet$ & (1) & (1) & (1) & 0 & 0 & 0 & $\bullet$ \\
\hline Schumacher et al. & $\bullet$ & (1) & $\bullet$ & (1) & 0 & D & 0 & $\bullet$ \\
\hline Jodlbauer \& Schagerl & $\bullet$ & - & (1) & 0 & 0 & D & 0 & 0 \\
\hline Leyh et. al. & $\bullet$ & $\bullet$ & $\bullet$ & (1) & $\bullet$ & 0 & 0 & 0 \\
\hline Batenburg et. al. & 0 & $\bullet$ & 0 & 0 & 0 & 0 & 0 & $\bullet$ \\
\hline Kloetzer \& Pflaum & $\bullet$ & - & (1) & (1) & 0 & 0 & 0 & $\bullet$ \\
\hline Back \& Berghaus & $\bullet$ & D & O & $\mathrm{O}$ & O & 0 & 0 & $\bullet$ \\
\hline Pfenning et. al. & $\bullet$ & $\bullet$ & $\bullet$ & 0 & 0 & 0 & 0 & D \\
\hline Vogelsang et. al. & 0 & 0 & $\bullet$ & 0 & 0 & $\bullet$ & 0 & o \\
\hline
\end{tabular}

Figure 3. Comparison of literature for relevant requirements

Based on a strong focus on engineering and digitalization aspects, the VPE-EDMM in this paper aims at an extension of existing models and tools and give detailed measurement criteria for assessment of vertical and horizontal PLC integration, MBSE Methods (based on VPE System Development Methodology) and also organizational issues.

\section{CONCEPTION OF THE VPE ENGINEERING DIGITALIZATION MATURITY MODEL}

The development procedure of the VPE-EDMM is based on the concept of Bruin et al. (2005), which suggests a set of successive development steps, and also the experience gained by the authors in developing maturity models (Siedler et al., 2020). The model development begins with the definition of the model scope or the model framework. This includes the focus and topic of the model, but also the potential addressees and from which area they should come. These questions can be answered with the goal of the work to design a maturity model for the current state of implementation of digitalization in engineering. The addressees are therefore engineering managers with sufficient overview of the processes and structures of the company. As mentioned Specific criteria of the model are derived out of VPE System Development Methodology, but also considers preliminary work on general aspects. The model can be used independently of the industry, but the model is mainly tailored to discrete and nondiscrete production companies. The model is given majorly a step-like representation that builds on each other, whereby all possible implementation states are represented.

\subsection{Model Architecture and its Components}

In order to facilitate a differentiated analyses of digitalized engineering maturity within the whole setup of a company, the proposed model includes a total of more than 80 maturity indicators which are grouped into 6 dimensions. Table 1 provides an overview on the dimensions together with some exemplary indicators to support understanding.

The dimensions "Engineering Processes and Tools" as well as "Products and Services Development" in engineering represent the objectives of digitalization of engineering (Nyffenegger et al., 2020). The other dimensions form the basis for achieving these goals. The exploitation of the potentials and perception of the needs associated with digitalization in the areas of "People," Organizational Culture and Structure and "Data Handling" play a key role here and form the foundation of digitalization (Carolis et al., 2017). Within each dimension, maturity criteria (Indicators) are defined and characteristics of the possible stages are specified with expressions. 
Table 1. Dimensions and indicators

\begin{tabular}{|c|l|}
\hline $\begin{array}{c}\text { Dimension } \\
\text { Tongineering Processes and } \\
\text { Tools }\end{array}$ & $\begin{array}{l}\text { Exemplary maturity indicators } \\
\text { Vertical Integration, Horizontal Integration (see 4.3) }\end{array}$ \\
\hline $\begin{array}{c}\text { Products and Services } \\
\text { Development } \\
\text { Data Handling }\end{array}$ & $\begin{array}{l}\text { MBSE Methods (modelling methods), Cybertronic Products } \\
\text { Development (sensors, connectivity, services, ...) } \\
\text { Big Data (handling of data amount, velocity, variety, ..), im- } \\
\text { plementation of Data Technologies (Iot, AI, ..) }\end{array}$ \\
\hline People (Spec. Engineers) & $\begin{array}{l}\text { Employee's Development and Involvement (digital compe- } \\
\text { tencies, Interdisciplinary competencies), Work Conditions }\end{array}$ \\
\hline Organizational Culture & $\begin{array}{l}\text { Enterprise Culture (decision making, communication), Strat- } \\
\text { egy (business model, innovation management) ... }\end{array}$ \\
\hline Organizational Structure & $\begin{array}{l}\text { Team structure (flat Structures, tools), Responsibilities (Chief } \\
\text { Digital Officer, Development Operation Units) }\end{array}$ \\
\hline
\end{tabular}

\subsection{Description of Maturity Levels}

The VPE-EDMM consists of four maturity levels: Explorer, Beginner, Advanced and Expert. These levels and their value range are shown in Figure 4 along with some formulas. In order to apply user specific priorities (e.g. Mechanical Design integration is more important to the user than Electrical Design), the maturity level can be weighted for each Indicator. This enables individualized comparison and decision making. The user evaluates Indicators based on provided expressions and defines his individual weightings and subsequently receives the results of Indicator Group and Dimension maturities.

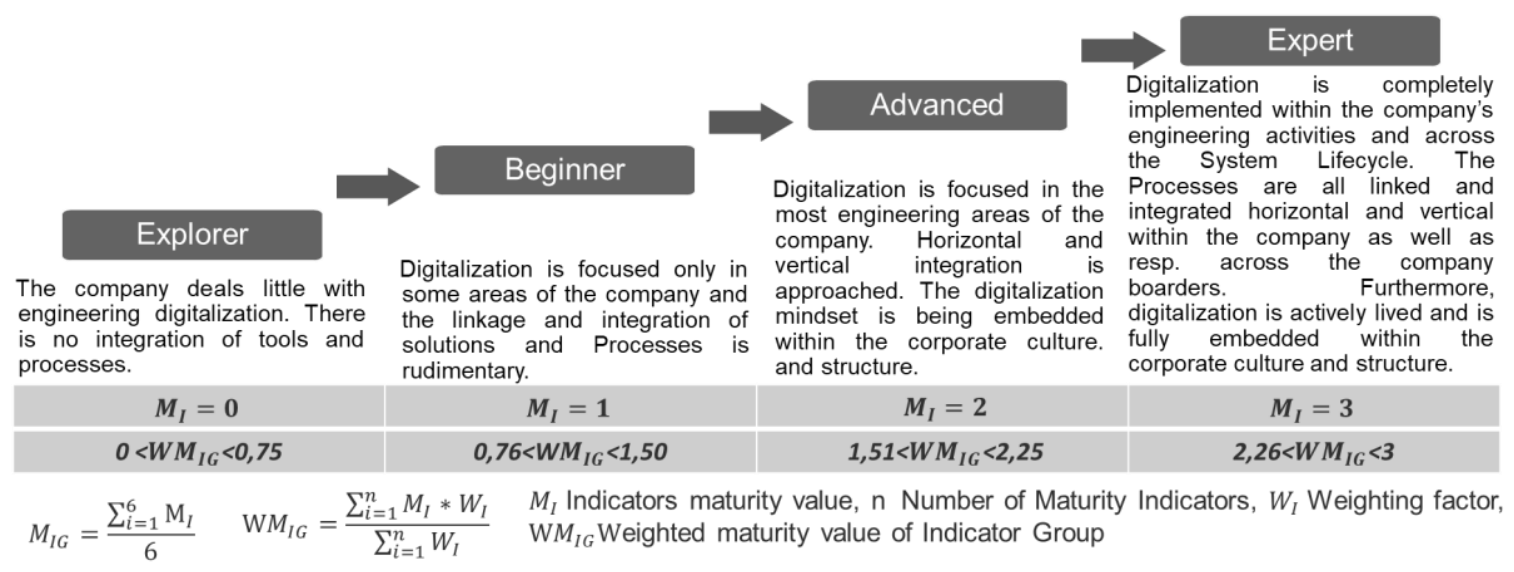

Figure 4. Maturity levels and values

\subsection{Exemplarily Execution of Selected Maturity Dimensions}

The following section focuses on the VPE-EDMM for digitalized engineering in the areas of horizontal and vertical integration. As discussed earlier in this paper, Digitalization of processes and tools can be seen as a frontline of digitalization in engineering, where, as in other fields of action, current and future market needs and the associated human, organizational and infrastructural requirements must be met.

In the upper section of Figure 5 a subset of the vertical integration matrix listing more common engineering applications for each PLC phase is shown. In this matrix the existence of the respective solutions and their degree of integration to a TDM (Team Data management System) or SysLM are queried. The highest level (evaluated for 3) is regarded for fully integration into the SysLM backbone.

In the second matrix (Figure 5) the horizontal integration and coupling of processes and data between the PLC phases is focussed. As covered in chapter 2.2. data and information existing in each PLC are to be connected and used for all its previous and succeeding phases. The horizontal integration evaluation matrix is to be filled out with scores for connection of PLCs according to the provided evaluation expressions. This symmetric matrix evaluates the degree of connectivity of each PLC to the next and previous one. Next to the matrix, a diagram presents the results of the evaluation. 


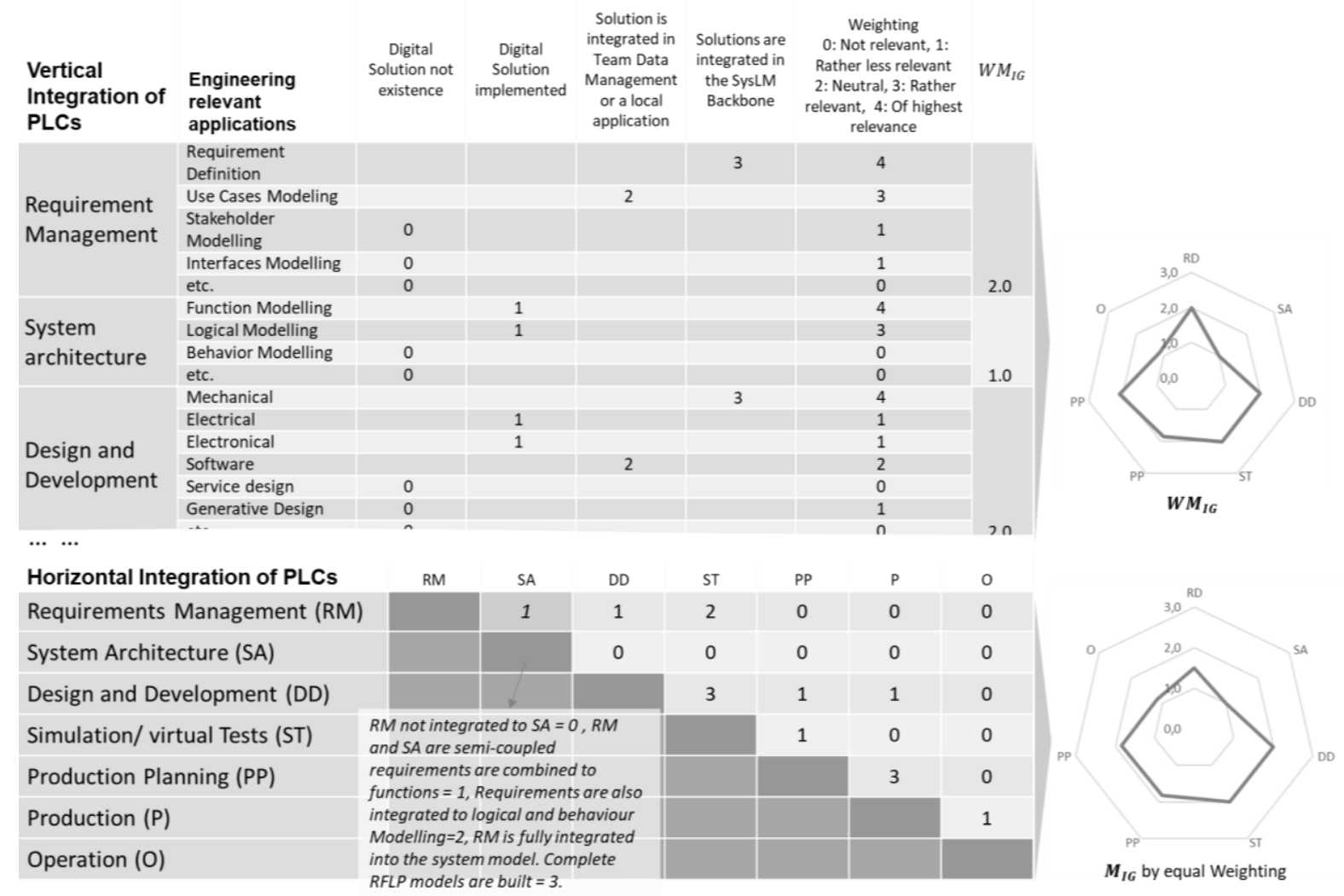

Figure 5. Segments of vertical and horizontal integration matrices

Further dimensions for evaluation of Personnel Development, Organizational Culture, Organizational Structure, Data Handling, Methods and Technologies are also designed as questionnaires (Figure 6).
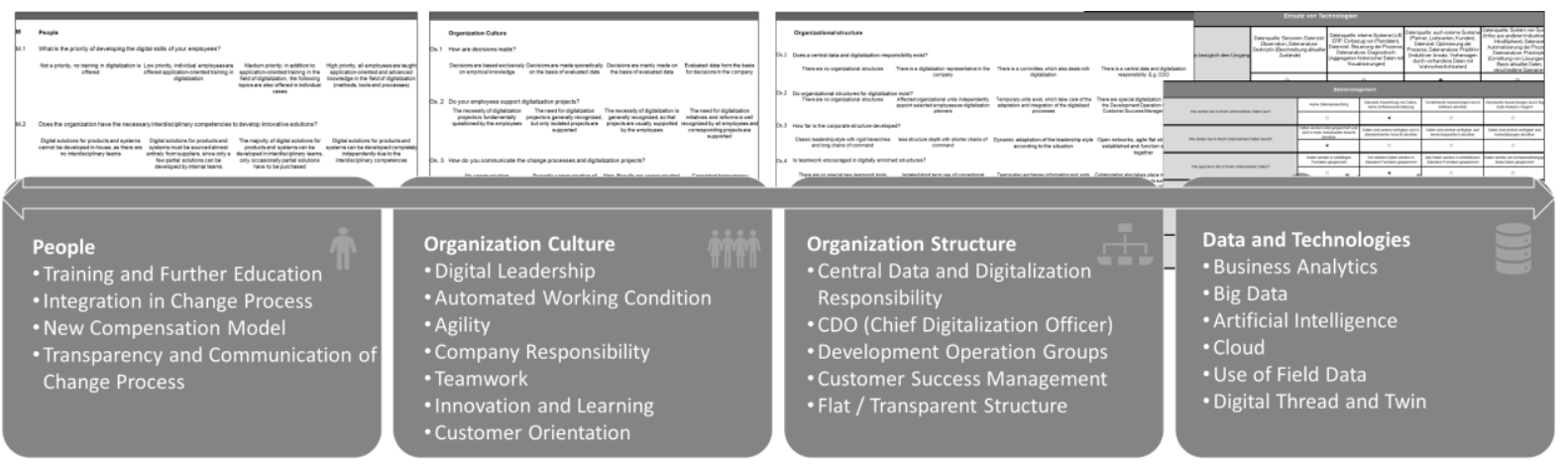

Figure 6. VPE-EDMM, more maturity dimensions

\section{OUTLOOK}

Based on the comprehensive maturity assessment, potentials for engineering digitization can be identified on the basis of which a strategy or an individual roadmap can be developed. In order to be able to carry out a targeted maturity assessment, fundamental company characteristics such as company size, business sector, market segment, organizational structures and existing strategies must be also recorded. The maturity of the individual competencies and skills should be determined, which can take place, for example, through surveys and interviews of employees. The maturity assessment is best done by people who are most familiar with the respective topics, such as development managers on issues related to quality in product development.

Further content of VPE-EDMM dimensions for evaluation of Personnel development, Organizational Culture, Organizational Structure and Data Handling as well as individual validation of results will be published later. More research can be done also on benchmark studies with relation to engineering capabilities. 


\section{REFERENCES}

Abramovici, M. (2018), "Engineering smarter Produkte und Services Plattform Industrie 4.0 STUDIE".

Ahern, D.M., Clouse, A. and Turner, R. (2003), CMMI distilled: A practical introduction to integrated process improvement, 2. ed., Addison-Wesley, Boston.

Ashton, K. (2009), “That 'internet of things' thing”, RFID journal, Vol. 22 No. 7, pp. 97-114.

Aurich, J.C., Koch, W. and Kölsch, P. (2019), Entwicklung datenbasierter Produkt-Service Systeme: Ein Ansatz zur Realisierung verfügbarkeitsorientierter Geschäftsmodelle, [1. Auflage].

Batenburg, R., Helms, R.W. and Versendaal, J. (2006), "PLM roadmap: stepwise PLM implementation based on the concepts of maturity and alignment", International Journal of Product Lifecycle Management, Vol. 1 No. 4, p. 333, https://dx.doi.org/10.1504/IJPLM.2006.011053.

Bauer, W., Stowasser, S., Mütze-Niewöhner, S., Zanker, C. and Brandl, K.-H. (Eds.) (2019), TransWork - Arbeit in der digitalisierten Welt: Stand der Forschung und Anwendung im BMBF-Förderschwerpunkt, Fraunhofer IAO, Stuttgart.

Becker, J., Knackstedt, R. and Pöppelbuß, J. (2009), "Developing Maturity Models for IT Management”, Business \& Information Systems Engineering, Vol. 1 No. 3, pp. 213-222, https://dx.doi.org/10.1007/s12599009-0044-5.

Berghaus, Sabine and Back, Andrea (2016), "Stages in Digital Business Transformation: Results of an Empirical Maturity Study", in MCIS 2016 Proceedings. 22.

Bruin, T., Freeze, R., Kaulkarni, U. and Rosemann, M. (Eds.) (2005), Understanding the main phases of developing a maturity assessment model.

Bundschuh, M., Dumke, R., Schmietendorf, A. and Ebert, C. (2005), Best practices in software measurement: How to use metrics to improve project and process performance ; with 37 tables, Springer, Berlin, Heidelberg, New York.

Carolis, A. de, Macchi, M., Negri, E. and Terzi, S. (2017), “A Maturity Model for Assessing the Digital Readiness of Manufacturing Companies”, in Lödding, H., Riedel, R., Thoben, K.-D., Cieminski, G. von and Kiritsis, D. (Eds.), Advances in production management systems: The path to intelligent, collaborative and sustainable manufacturing ; IFIP WG 5.7 International Conference, APMS 2017, Hamburg, Germany, September 3-7, 2017 ; proceedings, IFIP Advances in Information and Communication Technology, Vol. 513, Springer, Cham, pp. 13-20.

Crosby, P.B. (1979), Quality is free: The art of making quality certain, McGraw-Hill, New York.

Dickopf, T. (2020), A Holistic Methodology for the Development of Cybertronic Systems in the Context of the Internet of Things, Dissertation, Schriftenreihe VPE, Band 23, Martin Eigner (publ.), Kaiserslautern.

Eigner, M. (2014), "Modellbasierte Virtuelle Produktentwicklung auf einer Plattform für System Lifecycle Management", in Sendler, U. (Ed.), Industrie 4.0: Beherrschung der industriellen Komplexität mit SysLM, Xpert.press, Springer Vieweg, Berlin, Heidelberg, pp. 91-110.

Eigner, M. (2021), System Lifecycle Management: Digitalisierung des Engineering, Springer Vieweg, soon be published in English, Berlin, https://dx.doi.org/10.1007/978-3-662-62183-7.

Eigner, M., Dickopf, T. and Apostolov, H. (2019), "Interdisziplinäre Konstruktionsmethoden und -prozesse zur Entwicklung cybertronischer Produkte. Teil 2", Konstruktion.

Eigner, M., Koch, W. and Muggeo, C. (Eds.) (2017), Modellbasierter Entwicklungsprozess cybertronischer Systeme: Der PLM-unterstützte Referenzentwicklungsprozess für Produkte und Produktionssysteme, Springer Vieweg, Berlin.

Estefan, J.A. (2008), "Survey of Model-Based Systems Engineering (MBSE) Methodologies", available at: http://www.omgsysml.org/MBSE_Methodology_Survey_RevB.pdf.

Gausemeier, J., Bätzel, D. and Orlik, L. (2002), "Potenzialfindung im Rahmen der strategischen Produkt- und Prozessplanung”, ZWF, Vol. 97 No. 9, pp. 453-458, https://dx.doi.org/10.3139/104.100568.

Gausemeier, J., Wiesecke, J., Echterhoff, B., Isenberg, L., Koldewey, C., Mittag, T. and Schneider, M. (Eds.) (2017), Mit Industrie 4.0 zum Unternehmenserfolg - Integrative Planung von Geschäftsmodellen und Wertschöpfungssystemen: Cooperate succes with industry 4.0 - Integrative planning of business models and value creation systems, Heinz Nixdorf Institut Universität Paderborn, Paderborn.

Höhn, H., Sechser, B., Dussa-Zieger, K., Messnarz, R. and Hindel, B. (2015), Software Engineering nach Automotive SPICE: Entwicklungsprozesse in der Praxis ; Ein Continental-Projekt auf dem Weg zu Level 3, 1. Aufl., dpunkt, s.1.

Humphrey, W.S. (1988), "Characterizing the software process: a maturity framework", IEEE Software, Vol. 5 No. 2, pp. 73-79, https://dx.doi.org/10.1109/52.2014.

ISO (2015), Information Technology - Process Assessment - Requirements for process measurement frameworks: ISO/IEC JTC 1/SC 7 No. ISO/IEC 33003, 1st ed.

Issa, A., Lucke, D. and Bauernhansl, T. (2017), "Mobilizing SMEs Towards Industrie 4.0-enabled Smart Products”, Procedia CIRP, Vol. 63, pp. 670-674, https://dx.doi.org/10.1016/j.procir.2017.03.346.

Jodlbauer, H. and Schagerl, M. (2016), "Reifegradmodell Industrie 4.0 - Ein Vorgehensmodell zur Identifikation von Industrie 4.0 Potentialen”, in Mayr, H.C. and Pinzger, M. (Eds.), Informatik 2016: Tagung vom 26.-30. 
September 2016 in Klagenfurt, GI-Edition Lecture Notes in Informatics Proceedings, Gesellschaft für Informatik, Bonn, pp. 1473-1487.

Klötzer, C. and Pflaum, A. (2017), "Toward the Development of a Maturity Model for Digitalization within the Manufacturing Industry's Supply Chain”, in Hawaii International Conference on System Sciences- HICSS-50.

Leyh, C., Schäffer, T., Bley, K. and Forstenhäusler, S. (2016), "SIMMI 4.0 - A Maturity Model for Classifying the Enterprise-wide IT and Software Landscape Focusing on Industry 4.0", in Proceedings of the 2016 Federated Conference on Computer Science and Information Systems, 11.09.2016 - 14.09.2016, IEEE, pp. 1297-1302.

Lichtblau, K., Stich, V., Bertenrath, R., Blum, M. and Bleider, M. (2015), Industrie 4.0-Readiness, Frankfurt IMPULS-Stiftung VDMA.

Martin, J.N. (1997), Systems engineering guidebook: A process for developing systems and products, Systems engineering series, CRC Press, Boca Raton.

Nolan, R.L. (1973), "Managing the computer resource: a stage hypothesis", Communications of the ACM, Vol. 16 No. 7, pp. 399-405, https://dx.doi.org/10.1145/362280.362284.

Nyffenegger, F., Ríos, J., Rivest, L. and Bouras, A. (Eds.) (2020), Product Lifecycle Management Enabling Smart $X, I F I P$ Advances in Information and Communication Technology, Springer International Publishing, Cham.

Pfenning, P., Eibinger, H.C., Rohleder, C. and Eigner, M. (2020), “A Comprehensive Maturity Model for Assessing the Product Lifecycle", in Nyffenegger, F., Ríos, J., Rivest, L. and Bouras, A. (Eds.), Product Lifecycle Management Enabling Smart X, IFIP Advances in Information and Communication Technology, Vol. 594, Springer International Publishing, Cham, pp. 514-526.

Reichert, A. (2020), "Industrie 4.0 - Ansätze zur Strategieentwicklung in der Produktentwicklung”, Studienprojekt, Lehrstuhl für Virtuelle Produktentwicklung, TUK, Kaiserslautern, 2020.

Schuh, G., Anderl, R., Dumitrescu, R., Krüger, A. and Michael, t.H. (Eds.) (2020), Industrie 4.0 Maturity Index: Die digitale Transformation von Unternehmen gestalten - UPDATE 2020, acatech STUDIE, acatech, Deutsche Akademie der Technikwissenschaften e.V, München.

Schumacher, A., Nemeth, T. and Sihn, W. (2019), "Roadmapping towards industrial digitalization based on an Industry 4.0 maturity model for manufacturing enterprises", Procedia CIRP, Vol. 79, pp. 409-414, https://dx.doi.org/10.1016/j.procir.2019.02.110.

Siedler, C., Dupont, S., Tafvizi Zavareh, M., Zeihsel, F. and Aurich, J.C. (2020), "Reifegradmodell zur Bestimmung des Digitalisieurngsgrads", in Aurich, J.C., Pier, M., Siedler, C. and Sinnwell, C. (Eds.), Bedarfsgerechte Digitalisierung von Produktionsunternehmen: Ein modulares Transformationskonzept als praxisorientierter Ansatz., Synnovating, Kaiserslautern, 21-36.

Stich, V., Schumann, J.H. and Beverungen, D. (2019), Digitale Dienstleistungsinnovationen: Smart Services agil und kundenorientiert entwickeln, 1 st ed.

Tafvizi Zavareh, M., Sadaune, S., Siedler, C., Aurich, J.C., Zink, K.J. and Eigner, M. (2018), “A Study on the socio-technical Potentials of industrial Product Development Technologies for future digitized integrated Work Systems", in Proceedings of Norddesign 2018, Linköpig, Sweden.

VDA QMC Working Group 13 (2017), “Automotive SPICE® Process Reference Model Process Assessment Model. Version 3.1".

Vial, G. (2019), "Understanding digital transformation: A review and a research agenda", J. Strateg. Inf. Syst., https://dx.doi.org/10.1016/j.jsis.2019.01.003.

Vogelsang, A. (2018), "Reif für MBSE? Ein Reifegradmodell für modellbasiertes RE".

Wagner, T., Herrmann, C. and Thiede, S. (2017), "Industry 4.0 Impacts on Lean Production Systems", Procedia CIRP, Vol. 63, pp. 125-131, https://dx.doi.org/10.1016/j.procir.2017.02.041. 